\title{
Análisis de la expansión del olivar en la provincia de Jaén a través de fuentes cartográficas (1956-2007) ${ }^{1}$
}

\author{
Antonia PANIZA CABRERA \\ Departamento de Antropología, Geografía e Historia \\ Universidad de Jaén \\ apaniza@ujaen.es \\ Pilar GARCÍA MARTÍNEZ \\ Departamento de Antropología, Geografía e Historia \\ Universidad de Jaén \\ pgarcia@ujaen.es \\ José Domingo SÁNCHEZ MARTínEZ \\ Departamento de Antropología, Geografía e Historia \\ Universidad de Jaén \\ jdsanche@ujaen.es
}

Recibido: 15 de diciembre de 2014

Enviado a evaluar: 18 de diciembre de 2014

Aceptado: 27 de abril de 2015

\section{RESUMEN}

La provincia de Jaén es el ejemplo más radical de especialización olivarera del mundo, destinando a este cultivo más del $91 \%$ de su superficie agrícola. A través de fuentes cartográficas se reconstruye la expansión acaecida desde mediados del siglo XX, reparando en las claves espaciales de un proceso en el que ha predominado la estrategia de sustitución de otros usos agrícolas antes que la expansión de la frontera agrícola. Igualmente se identifican algunas de las características actuales de este monocultivo extremo, entre ellas las que permiten entender su elevada productividad global (incremento de la superficie regada, ocupación de suelos de mejores condiciones agronómicas) o la convivencia de olivares de muy diferente paisajística y potencialidad económica.

Palabras clave: Andalucía, Geografía Rural, monocultivo olivarero, cartografía temática, usos del suelo.

\footnotetext{
${ }^{1}$ Este trabajo se enmarca en el Proyecto de Investigación de Excelencia "Caracterización y perspectivas del monocultivo olivarero jiennense: conformación espacio-temporal, diversidad paisajístico-agronómica y dinámicas territoriales inmediatas", financiado por la Consejería de Economía, Innovación y Ciencia de la Junta de Andalucía (SEJ - 1153, convocatoria 2012).
} 


\title{
Analysis of the expansion of the olive grove in the province of Jaén through cartographic sources (1956-2007)
}

\begin{abstract}
The province of Jaen is the most radical example of olive specialization of the world, destining to the olive groves more than $91 \%$ of its agricultural surface. Through cartographic sources of expansion took place from middle of the 20th century is reconstructed, stressing in the spatial keys of a process in which there has predominated the strategy of substitution of other agricultural uses before that the expansion of the agricultural frontier. Likewise, there are identified some of the current characteristics of this extreme monoculture, between them those who allow us to understand its high global productivity (increase of the irrigated surface, take up of soils of better agronomic conditions) or the coexistence of olive groves of very different landscape and economic potential.
\end{abstract}

Key words: Andalucía, Rural Geography, olive monoculture, thematic Cartography, land uses.

Le panier de biens et services en tant qu'outil de diagnostic territorial: Le cas de la wilaya d'Ain-Témouchent (Algerie)

\section{RÉSUMÉ}

La province de Jaén est exemplaire dans le monde entier pour son oléiculture, car plus de $91 \%$ de ses terres agricoles sont consacrées à l'olivier. Les sources cartographiques permettent de reconstruire l'extension qui a lieu depuis la seconde moitié du XXe siècle, selon laquelle on remarque un processus qui a privilégié de remplacement d'autres cultures plutôt que l'expansion de la frontière agricole. On y identifie également quelques-unes des fonctionnalités actuelles de cette monoculture extrême, dont celles qui permettent de comprendre sa productivité globale élevée (augmentation de la superficie irriguée, occupation des sols de meilleures conditions agronomiques) ou la coexistence des oliveraies très différentes selon le paysage et le rendement économique.

Mots clés: Andalousie, Géographie rurale, monoculture de l'olive, cartographie thématique, utilisation du sol.

\section{INTRODUCCIÓN}

Como resultado sinérgico de favorables condiciones edafo-climáticas y políticoeconómicas, en la provincia de Jaén se ha conformado durante las últimas décadas el que puede ser el ejemplo más exagerado de especialización productiva regional de toda la Unión Europea. En el momento presente este monocultivo olivarero ha avanzado hasta ocupar el $91 \%$ de la superficie agrícola, mediante un proceso de expansión que parece no haber llegado a su fin y que contemplado en perspectiva histórica resulta verdaderamente espectacular: a mediados del siglo XVIII esta planta apenas ocupaba 39 mil ha, al comenzar el siglo XX se superaron las 200 mil ha y en estos momentos son más de 584 mil ha. El olivar es además bastante uniforme desde la perspectiva de la variedad dominante (picual) y por el destino de la aceituna, masivamente dedicada a la producción de aceite de oliva. No obstante, la heterogeneidad es importante si se consideran la intensidad de los métodos de cultivo, 
los contrastes fisiográficos o la estructura de la propiedad (Sánchez y Gallego, 2011). De hecho, en términos de producción se observa un importante desfase entre los modelos más productivistas y los denominados genéricamente como tradicionales. En la práctica eso significa que en las primeras se puede obtener sobre una unidad de superficie la misma cantidad de fruto que la lograda en 15 ó 20 unidades de los tipos más marginales (Guzmán et al, 2009).

El caso es que en conjunto esta provincia procura más aceite que el obtenido en países enteros como Italia o Grecia (que son el segundo y el tercer productor mundial respectivamente), un hecho que se explica por la primacía de un modelo muy productivista (Rodríguez et al., 2013). El objetivo es la búsqueda a toda costa de las mayores cantidades posibles de aceite antes que otros fines igualmente interesantes, como la obtención de un producto de mayor calidad o la posibilidad de que los productores intervengan de forma más decisiva a lo largo de la cadena de valor, pues ahora son insignificantes en las fases de envasado y de comercialización minorista (MARM, 2010).

Así, junto al incremento de la superficie regada en un cultivo que siempre fue de secano (sin embargo en la actualidad se calcula que el olivar regado supera las 270 mil ha) y otros factores de intensificación productiva, se sigue apostando por reducir el número de almazaras y, en consecuencia, hacerlas cada vez con mayor capacidad industrial para conseguir economías de escala $\mathrm{y}$, en definitiva, para asentar una estrategia competitiva basada en la reducción de costos (Araque, 2010). Este modelo agroindustrial, claramente contrapuesto al dominante en otros países como Italia, Francia y los nuevos productores extra-mediterráneos (California, el centro de Chile o Australia occidental por poner algunos ejemplos), se fundamenta también en la presencia de una importante estructura cooperativa, el predominio del minifundio (la superficie media por explotación es inferior a $5 \mathrm{ha}$ ) y la presencia destacada de agricultores no profesionales (Sánchez, et al., 2011; USITC, 2013).

En el presente trabajo nos proponemos analizar cuál ha sido el proceso de expansión del olivar acudiendo a las fuentes cartográficas disponibles, en particular desde mediados del siglo XX, un momento en el que de manera definitiva se desata la lógica capitalista que está detrás de esta especialización productiva extrema. Queremos destacar, no obstante, que la posibilidad de reconstruir espacialmente la mancha olivarera se remonta a finales del siglo XIX. En aquellos momentos, la preocupación era contar con un catastro de la propiedad rústica preciso sobre el que fundar un sistema fiscal justo y coherente, capaz de superar en todo caso los ocultamientos que se producían en los padrones de contribuyentes y los amillaramientos. La respuesta vino de la mano del Instituto Cartográfico y Estadístico, cuyos topógrafos procedieron a levantar planos a escala 1:25.000 donde se recogía con gran detalle y precisión los usos del suelo. De los trabajos iniciales que hemos hecho con dichos planos, se constata el proceso de ocupación de suelos de anterior uso forestal y la sustitución de otros destinados al cultivo de cereal o dehesa. En términos generales la conclusión provisional es que el olivar se reservaba entonces para los suelos menos fértiles, de mayor pendiente y casi siempre en secano. En 
definitiva, un modelo aún lejano al que se pone a punto cuando las diferentes "revoluciones verdes" del siglo XX hacen su aparición.

Nuestro interés ahora es, precisamente, centrarnos en la explotación de las fuentes aparecidas durante el siglo XX, comenzando por la fotografía aérea procedente del denominado "vuelo americano" (1956-1957) y terminando en las últimas imágenes de satélite donde se plasma la consolidación del "mar de olivos" que hoy domina el paisaje agrario provincial.

\section{2. ÁREA DE ESTUDIO}

Localizada en la porción nororiental de la Comunidad Autónoma de Andalucía, la provincia de Jaén (fig.1), limita con las de Córdoba (Oeste), Ciudad Real (Norte), Granada (Sur) y Albacete (Este). De acuerdo con los datos ofrecidos por el INE ${ }^{2}$, cuenta una superficie total de $13.496 \mathrm{~km}^{2}$ repartidos entre 97 municipios. En ella se concentran poco más de 670 mil habitantes, lo que representa el $8 \%$ de la población andaluza y la densidad más baja de la región, con apenas $49,6 \mathrm{hab} . / \mathrm{km}^{2}$.

Figura 1. Área de Estudio.

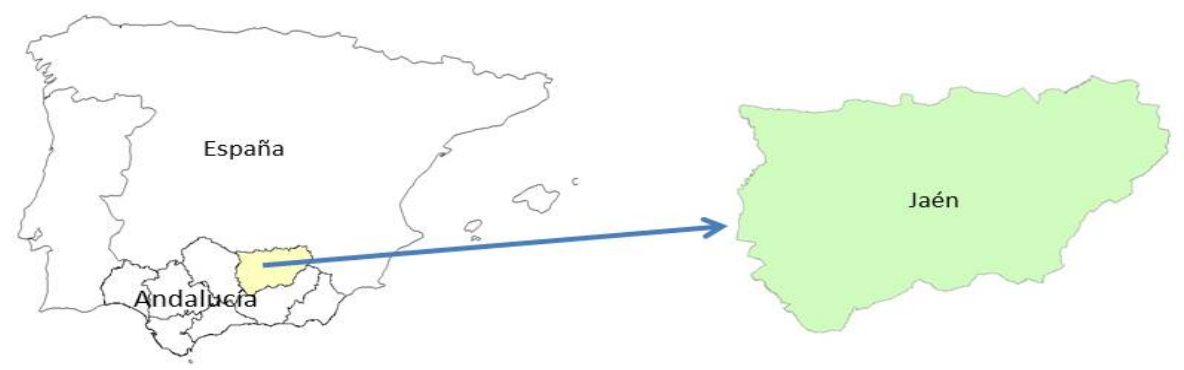

Fuente: Elaboración propia.

Excepto en su porción occidental y central, donde hace acto de presencia el Valle del Guadalquivir, la provincia está cruzada por diferentes cordilleras montañosas ${ }^{3}$. Al norte hace su aparición Sierra Morena, de modestas altitudes y límite con la Meseta castellana. Las Cordilleras Béticas, en concreto diferentes sierras pertenecientes a la

$2 \mathrm{http}: / /$ www.ine.es/inebaseweb/pdfDispacher.do?td=154090\&L=0 (acceso $\quad$ del 4 de noviembre de 2014).

3 Para la breve descripción fisiográfica que sigue nos hemos basado en el Atlas de Andalucía (Junta de Andalucía, 2005). 
zona Subbética, por su parte, ocupan el sur y el oriente provincial. Fruto de esta variedad de unidades geomorfológicas se encuentran materiales geológicos contrastados: en el Macizo Hespérico dominan los paleozoicos del zócalo meseteño (granitos, pizarras, cuarcitas y areniscas); los materiales terciarios aparecen en la cobertera tabular que supone el espacio de transición entre Sierra Morena y el Valle del Guadalquivir; dentro de esta depresión alpina los materiales sedimentarios margoarcillosos de relleno son de edad Cenozoica; en las Béticas encontramos rocas de naturaleza calcárea (calizas, margas y dolomías) de edad Mesozoica. Igualmente, se puede suponer el contraste tectónico entre estas zonas, con estructuras fracturadas, horizontales y plegadas respectivamente (Ruiz, 1997; Molina, 1997).

Los suelos son en su mayoría pobres y poco evolucionados, destacando los luvisoles, litosoles, regosoles, vertisoles y cambisoles. Por su parte, el clima es típicamente mediterráneo, con una larga sequía veraniega extendida entre junio y octubre, si bien la altura, orientación y la diferente incidencia de los flujos del oeste imponen modificaciones locales. Las precipitaciones medias se sitúan entre los $300 \mathrm{y}$ los $600 \mathrm{~mm}$ en las zonas de campiña, pero se elevan por encima de los 1000 en zonas de montaña, especialmente la Sierra de Cazorla. Las temperaturas medias oscilan entre $\operatorname{los} 18^{\circ} \mathrm{C}$ de media en las zonas de la depresión del Guadalquivir a los $10^{\circ} \mathrm{C}$ de las zonas más elevadas. Estas condiciones harían del bosque esclerófilo la formación vegetal climácica de la mayor parte del territorio, pero esta ha sido intensamente transformada tanto a través de procesos de destrucción y alteración como de reconstrucción, siendo en este sentido las repoblaciones forestales con coníferas un elemento primordial del paisaje vegetal de las zonas montañosas.

La presencia de tierras bajas es casi testimonial (tan solo un $0,6 \%$ del territorio está por debajo de los 200 m.s.n.m.); por encima de los 1.000 m.s.n.m. se distribuye el 20,1\%, siendo anecdótica la superación de los 2.000 m.s.n.m. (tan solo en algunos picos destacados de Sierra Mágina y Sierra de Cazorla). Con ello, podemos considerar que la mayor parte del solar se encuentra dentro de un rango de condiciones relativamente favorables para el desarrollo de las actividades agrarias.

Las clases de capacidad de uso agrícola (Junta de Andalucía, 1987), en este sentido, son una magnífica síntesis de la combinación de variables fisiográficas (pendiente, suelo, clima) e indicador de base de las posibilidades que encuentran las diferentes actividades que están presentes en el territorio. Agrupando las tierras que tienen capacidad agrícola y las que no están dotadas para esta finalidad, prácticamente tenemos la misma cantidad. Estas dos mitades, la agrícola y la forestal, presentan una relativa amplitud de usos, pero cada una de ellas está claramente dominada por paisajes prototípicos. En efecto, cuando revisamos la distribución general de usos y coberturas ${ }^{4}$ de la provincia (2007) se confirma lo que ya hemos explicado sobre el cultivo olivarero como uso predominante en el caso de las tierras agrícolas; mientras

${ }^{4} \mathrm{http}: / /$ www.juntadeandalucia.es/medioambiente (acceso del 4 de noviembre de 2014). 
que las superficies forestales que se encuentran arboladas (agrupamos aquí desde las formaciones forestales densas hasta los matorrales y pastizales con arbolado), juegan ese mismo papel en el grupo de tierras agrarias sin vocación agrícola ${ }^{5}$.

\section{MATERIAL Y MÉTODOS}

La disponibilidad de cartografía temática a partir de la cual constatar la localización de la mancha olivarera y la expansión que ha venido experimentando este cultivo durante el período de tiempo considerado para este trabajo, se inicia con la explotación de la fotografía aérea de mediados del siglo XX. No obstante, la primera cartografía específica de la que tenemos constancia, donde se recoge específicamente esta información data de dos décadas más tarde, con motivo de la publicación del Inventario Agronómico del Olivar (Ministerio de Agricultura, 1975). Este trabajo, realizado a los efectos de promover planes de mejora y modernización para lo que entonces era considerado como un "cultivo-problema", recoge en efecto planos de escala 1:200.000 dedicados a las diferentes comarcas olivareras que se establecen en dicho documento. En particular, para la provincia de Jaén se confeccionaron un total de ocho planos de localización de manchas de olivar, cuya suma total se elevaba entonces a $434.999 \mathrm{ha}$.

De gran interés resulta también el Mapa de Cultivos y Aprovechamientos de la Provincia de Jaén (MAPA, 1986), de igual escala al anterior y síntesis de las hojas a escala 1:50.000 que el Ministerio fue publicando de cada una de las hojas del Mapa Topográfico Nacional con igual finalidad. Cabe señalar que el mapa diferencia por primera vez el olivar regado (52.093 ha) del olivar en secano (411.238 ha).

Durante los años 90 y con posterioridad se han multiplicado las fuentes para la realización de cartografía temática, tanto a través de la fotografía aérea convencional como a partir de la teledetección ${ }^{6}$. Con ello, se ha facilitado el trabajo y la precisión con la que podemos medir y referenciar espacialmente este proceso. En cualquier caso, nosotros hemos seleccionado dos momentos para realizar y comparar la cartografía del olivar jiennense: 1956 y 2007. Se ha recurrido como fuente principal de datos a la información digital, de tipo vectorial, contenida en el mapa de usos y coberturas a escala 1:25.000 realizada por la Junta de Andalucía. Esta base es el resultado de la interpretación fotogramétrica de las ortofotos de 1956 y 2007 . La ortofotografía utilizada para 1956, en blanco y negro, tiene una escala aproximada de 1:33.000, mientras las ortoimágenes de 2007 (en color), presentan una resolución de 1 metro.

${ }^{5}$ En concreto, para ese año el olivar ocupaba 570.291 ha de un total de 657.913 ha agrícolas; por su parte, los terrenos arbolados alcanzaban 454.326 ha sobre un total de 633.430 ha de superficies forestales y naturales.

${ }^{6}$ http://www.juntadeandalucia.es/institutodeestadisticaycartografia 
Estas fuentes de información nos han permitido construir los mapas del olivar en la provincia de Jaén para ambas fechas. Para ello ha sido necesario seleccionar del conjunto de la base de datos las categorías que hacen referencia al olivar. Tras la definición de las categorías de olivar se ha procedido a su selección de la base de datos espacial original, con la aplicación de la herramienta "selección-selección por atributos" del Software ArcGis 10, y como resultado se han obtenido dos nuevas bases de datos espaciales con las tipologías de olivar para las fechas de 1956 y 2007, respectivamente. A partir de ellas ha sido posible la generación y edición de los mapas de olivar de 1956 y 2007.

Para obtener el mapa representativo de la evolución de la superficie de olivar en la provincia de Jaén se ha utilizado la función "erase" (borrar) dentro de las herramientas de análisis (superposición) del SIG. Esta herramienta crea una nueva capa a partir de las entidades o porciones que caen fuera de los límites de la capa "erase", que se copian en la capa resultante. En este caso la capa de entrada ha sido la de 2007 y la capa de recorte la elaborada con los datos de 1956. En la figura 1 se presenta la distribución del olivar en 1956 y 2007, apreciándose el incremento entre ambos momentos.

Figura 1. Distribución espacial del olivar en 1956 y su expansión hasta 2007.

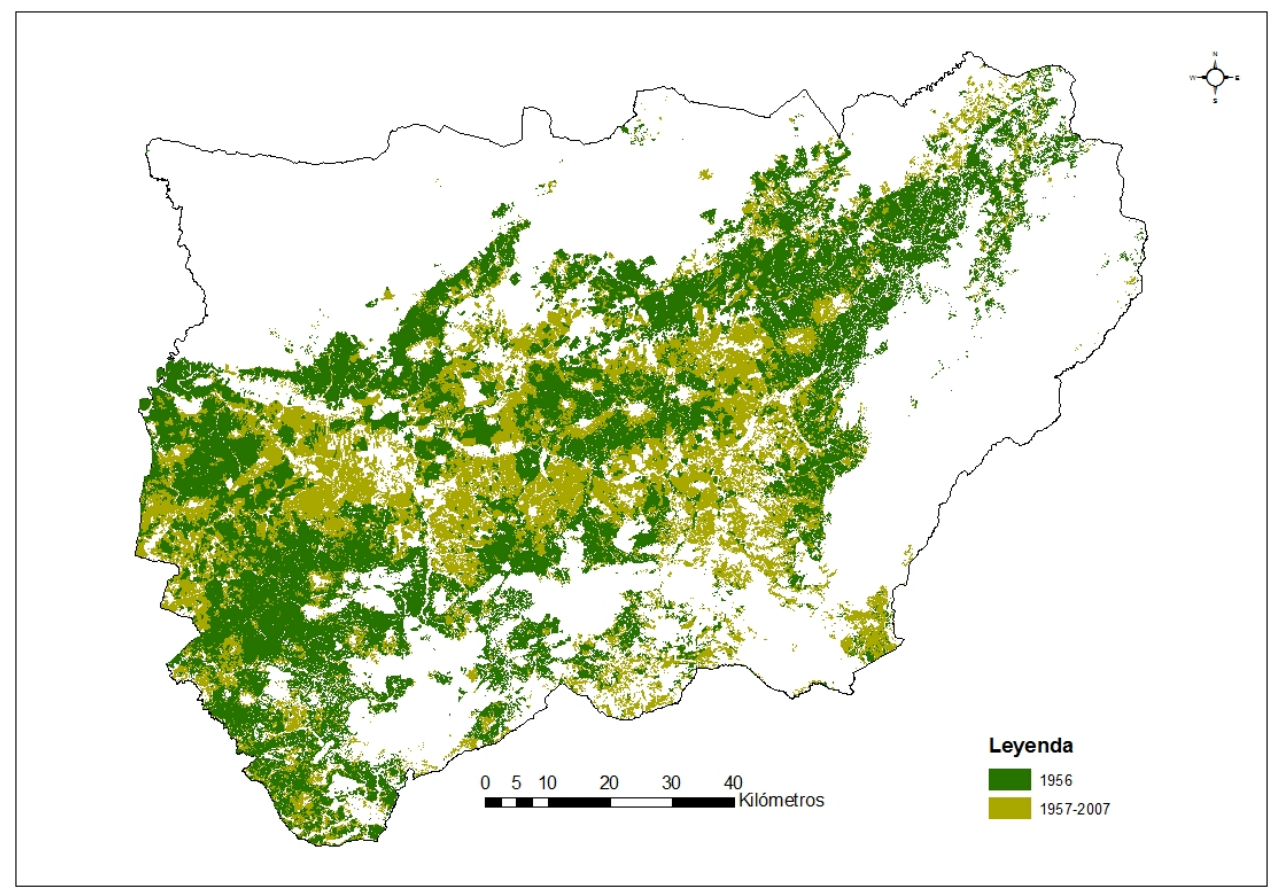

Fuente: Elaboración propia. 
Al estar constituida cada capa por una de las bases de datos espacial, ha sido posible su exportación a Microsoft Excel para el tratamiento estadístico de la información y para la generación de los gráficos que nos permiten corroborar y comparar, tanto numérica como gráficamente, la evolución de los paisajes de olivar entre ambas fechas, y que han sido utilizados como apoyo al análisis espacial de su distribución en la provincia de Jaén.

Para la representación cartográfica y el análisis estadístico de los datos obtenidos en la capa de cambios entre las fechas de 1956 y 2007 ha sido necesario agrupar los distintos usos en un número más reducido de categorías, como podemos ver en la tabla 1, lo que nos ha permitido generar una cartografía más legible. Para denominar a estos grupos se ha tomado como referencia el nombre del uso más abundante en cada uno de los casos.

Tabla 1. Agrupación de usos en grandes categorías.

\begin{tabular}{|c|c|}
\hline Grupo & Usos incluidos \\
\hline Urbano & $\begin{array}{l}\text { Urbanizaciones agrícolas/residenciales; Zonas industriales y comerciales; Complejos } \\
\text { ferroviarios; Zonas mineras. }\end{array}$ \\
\hline Riberas & $\begin{array}{l}\text { Ríos y cauces naturales: bosques de ribera; Ríos y cauces naturales: otras formaciones } \\
\text { riparias; Lagunas continentales; Embalses. }\end{array}$ \\
\hline $\begin{array}{l}\text { Herbáceos en } \\
\text { secano }\end{array}$ & $\begin{array}{l}\text { Cultivos herbáceos en secano; Mosaicos de cultivos y vegetación natural: cultivos } \\
\text { herbáceos y pastizales; Cultivo herbáceo arbolado: quercíneas densas; Cultivo herbáceo } \\
\text { arbolado: quercíneas dispersas }\end{array}$ \\
\hline $\begin{array}{c}\text { Leñosos en } \\
\text { secano }\end{array}$ & $\begin{array}{l}\text { Cultivos leñosos en secano: viñedo; Otros cultivos leñosos en secano: frutales en secano; } \\
\text { Asociaciones y mosaicos de cultivos leñosos en secano: olivar-viñedo; Otras asociaciones y } \\
\text { mosaicos de cultivos leñosos en secano; Mosaicos de cultivos y vegetación natural. } \\
\text { Cultivos leñosos y pastizal; Mosaicos de cultivos y vegetación natural. Cultivos leñosos y } \\
\text { vegetación natural leñosa; Otros mosaicos de cultivos y vegetación natural; Olivar } \\
\text { abandonado; Otros cultivos leñosos abandonados. }\end{array}$ \\
\hline $\begin{array}{l}\text { Herbáceos en } \\
\text { regadío }\end{array}$ & $\begin{array}{l}\text { Otros cultivos herbáceos regados; Cultivos herbáceos en regadío. Regados y no regados; } \\
\text { Cultivos herbáceos en regadío. No regados; Mosaicos de secanos y regadíos con cultivos } \\
\text { herbáceos; Mosaicos de secanos y regadíos con cultivos herbáceos y regadíos. }\end{array}$ \\
\hline $\begin{array}{l}\text { Leñosos en } \\
\text { regadío }\end{array}$ & $\begin{array}{l}\text { Otros cultivos leñosos en regadío. Otros frutales en regadío; Áreas heterogéneas en } \\
\text { regadío. Mosaico de leñosos en regadío. }\end{array}$ \\
\hline $\begin{array}{l}\text { Mixto leñoso- } \\
\text { herbáceo, secano- } \\
\text { regadío }\end{array}$ & $\begin{array}{l}\text { Áreas agrícolas heterogéneas de cultivos herbáceos y leñosos en secano; Áreas agrícolas } \\
\text { heterogéneas en regadío. Cultivos herbáceos y leñosos en regadío; Mosaicos de cultivos y } \\
\text { vegetación natural. Herbáceos y vegetación natural leñosa. }\end{array}$ \\
\hline Arbolado & $\begin{array}{l}\text { Formaciones arboladas densas: quercíneas; Formaciones arboladas densas: coníferas; } \\
\text { Formaciones arboladas densas: eucaliptos; Formaciones arboladas densas: otras frondosas. }\end{array}$ \\
\hline Matorral & $\begin{array}{l}\text { Matorral denso arbolado: quercíneas densas; Matorral denso arbolado: quercíneas } \\
\text { dispersas; Matorral denso arbolado: coníferas densas; Matorral denso arbolado: coníferas } \\
\text { dispersas; Matorral denso arbolado: otras frondosas; Matorral disperso arbolado: } \\
\text { quercíneas densas; Matorral disperso arbolado: quercíneas dispersas; Matorral disperso } \\
\text { arbolado: coníferas densas; Matorral disperso arbolado: coníferas dispersas; Matorral } \\
\text { disperso arbolado: eucaliptos; Matorral denso; Matorral disperso con pastizal; Matorral } \\
\text { disperso con pasto y roca o suelo. }\end{array}$ \\
\hline Pastizal & $\begin{array}{l}\text { Pastizal arbolado: quercíneas densas; Pastizal arbolado: quercíneas dispersas; Pastizal } \\
\text { arbolado: coníferas densas; Pastizal arbolado: coníferas dispersas; Pastizal arbolado: otras } \\
\text { frondosas; Pastizal continuo; Pastizal con suelo o roca desnudos; Roquedos y suelo } \\
\text { desnudo; Zonas sin vegetación por roturación. }\end{array}$ \\
\hline
\end{tabular}

Fuente: Elaboración propia. 


\section{RESULTADOS}

La comparación de las cifras obtenidas a partir de la explotación de las fuentes cartográficas nos permite medir el aumento superficial experimentado por el olivar en la provincia de Jaén de forma alternativa a los recuentos estadísticos publicados por los organismos oficiales encargados de esta labor. En tal sentido, lo primero que hay que aclarar es la no coincidencia de estas cantidades, si bien las diferencias no son excesivamente importantes $\mathrm{y}$, desde luego, no ponen en cuestión las grandes tendencias que nosotros hemos detectado. Así, para 1956 el Anuario de Estadística Agraria recoge una superficie total de $353.150 \mathrm{ha}$, mientras que el análisis de la fotografía aérea la eleva a 355.378 ha. Esta discrepancia se reduce en el año 2007 a unas mil cuatrocientas hectáreas, si bien en este caso a favor del recuento cartográfico (570.852 frente a 569.386 ha). Por descontado, asumimos que el error pueda derivarse del proceso de fotointerpretación, si bien insistimos en que esta no es ahora nuestra preocupación mayor.

En todo caso, entre ambas fechas, las fuentes cartográficas ofrecen una expansión del olivar de más de 215 mil ha, es decir, un crecimiento superior al 60\%. Esta es la traducción, en lo superficial, de los profundos cambios que experimenta durante estas décadas el mundo rural jiennense. Mediados de los cincuenta se puede considerar como el momento de auge del repliegue hacia el campo que se produce después de la Guerra Civil española. La población rural y empleada en el sector agrario conoce entonces sus máximos históricos y, en buena lógica con la falta de medios para la intensificación, es natural la mayor diversificación de los usos del suelo, la elevada significación de las tierras dedicadas al cereal y la expansión de la actividad agraria por todos aquellos suelos que pudieran tener una mínima capacidad para producir alimentos.

La imagen reflejada en los mapas de la primera década del siglo XXI, sin embargo, nos muestran el resultado final de un proceso marcado por la progresiva orientación a los estímulos de un mercado que se iba globalizando. La especialización extrema vivida en esta provincia es un ejemplo claro que profundiza en la vocación hacia la exportación de un producto que desde sus orígenes tenía ya esta orientación, pero que ahora alcanzará cotas extraordinarias. En otros lugares nos hemos ocupado de los principios que han alentado este comportamiento y la intensificación productiva que ha conllevado, demostrando igualmente que las cosechas actuales son mayores no tanto por la expansión física del cultivo como por el incremento de los rendimientos (Sánchez, 2012).

La verdad es que comparar en términos brutos la superficie de 1956 con la actual es un ejercicio fútil, pues las formas de manejar los recursos, el diseño de las plantaciones que se han ido incorporando y, como resultado de todo ello, los rendimientos de aceituna y aceite son extraordinariamente dispares. Eso sí, en parte, estas diferencias se deben también a la calidad del suelo destinado al olivar en cada momento, y este aspecto es perfectamente reconocible en la cartografías presentada (figura 2). En efecto, se observa que las zonas en las que se ha producido la 
sustitución de cultivos ha llevado progresivamente al olivar a los suelos más productivos y fáciles de gestionar con medios mecánicos. En efecto, el mayor incremento se ha producido en la zona central de la provincia, sobre los materiales sedimentarios que conforman el típico paisaje de campiña en el valle del Guadalquivir. En su mayoría, se trataba de tierras hasta entonces dedicadas a cereales de secano (véase tabla 2). Más llamativo es, si cabe, la expansión a través de roturación de tierras dedicadas a la ganadería (matorrales, pastizales e incluso zonas arboladas); se trata de casos que en condiciones normales, dada la dificultad para trabajarlas, habrían ido evolucionando al margen de la intervención humana por su abandono o, como mucho, manteniendo un uso ganadero extensivo. Las condiciones político-económicas que el olivar conoció a raíz de la adhesión de España a la Unión Europea explican, no obstante, su roturación o intensificación, algo verdaderamente excepcional; como también lo es el mantenimiento de olivares en situación de marginalidad ecológica (sobre este aspecto volveremos más tarde).

Figura 2. Usos sustituidos por la expansión del olivar entre 1957 y 2007.

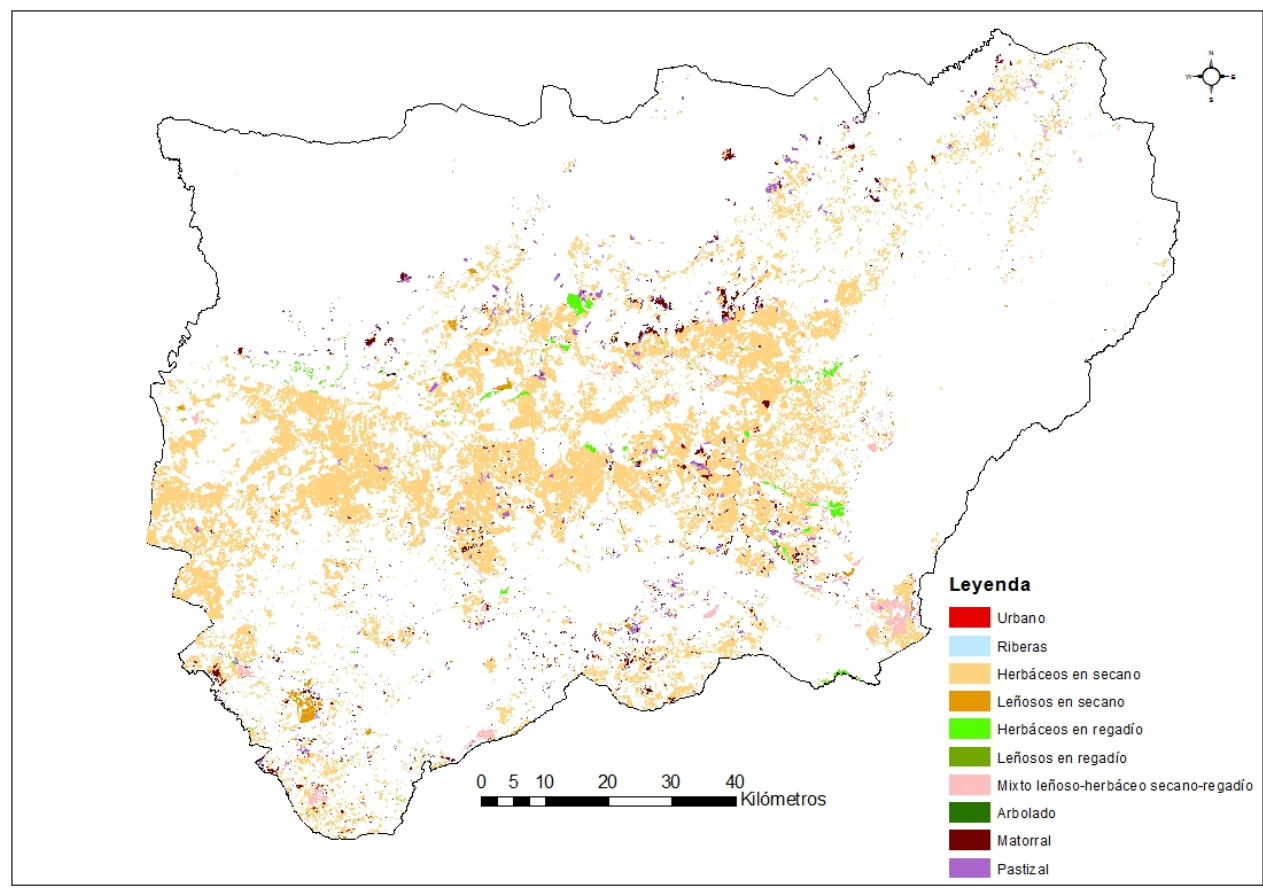

Fuente: Elaboración propia. 
Entre los paisajes agrarios que han ido sucumbiendo se encuentra el adehesado, como se ha tenido oportunidad de constatar en estudios de escala municipal en territorios donde este uso tenía mayor significación en el pasado, como es el caso de las comarcas de Sierra Morena o El Condado (Paniza, 2010). Igualmente ocurre con otros usos característicos de anteriores modelos de utilización de los recursos, como los que implicaban la mixtura de ganadería y agricultura o la existencia de manchas agrícolas promiscuas, entre las cuales no era infrecuente que se asociara el olivar con otros leñosos o cereales. Esto había sido frecuente durante la etapa anterior a 1956. Así, a finales del XIX se estimaban en 35.000 ha de esta particular agricultura promiscua (Dirección General, 1888). Y un siglo más tarde aún se reconocían 116 ha de asociación de olivar y viñedo (MAPA, 1986). A día de hoy, este tipo de paisajes pueden considerarse residuales.

Tabla 2. Expansión del olivar de acuerdo al anterior uso del suelo (1956-2007).

\begin{tabular}{|l|c|c|}
\hline \multicolumn{1}{|c|}{ Uso anterior } & Superficie (ha) & Superficie (\%) \\
\hline Herbáceos en secano & $196.603,27$ & 86,21 \\
\hline Matorral & $8.666,32$ & 3,80 \\
\hline Pastizal & $7.797,22$ & 3,42 \\
\hline Mixto herbáceo-leñoso secano-regadío & $7.182,40$ & 3,15 \\
\hline Herbáceos en regadío & $3.797,76$ & 1,67 \\
\hline Leñosos en secano & $3.548,26$ & 1,56 \\
\hline Riberas & 241,44 & 0,11 \\
\hline Leñosos en regadío & 86,25 & 0,04 \\
\hline Arbolado & 73,86 & 0,03 \\
\hline Urbano & 41,85 & 0,02 \\
\hline Total & $228.038,63$ & 100 \\
\hline
\end{tabular}

Fuente: Elaboración propia.

Otro hecho destacado es el avance olivarero por zonas previamente irrigadas. El olivar se consideró siempre un cultivo de secano y tradicionalmente tan solo se regaban árboles exentos, cultivados como un frutal más en zonas de huerta o pequeñas parcelas junto a manantiales o en las inmediaciones de los cursos fluviales, realizándose en estos casos mediante la construcción de pozas o por inundación. La expansión del regadío en la provincia conoció un extraordinario auge durante las décadas centrales del siglo XX, a través de grandes zonas regables que plasmaban la capacidad derivada de la entrada en funcionamiento de embalses de gran capacidad. Ahora bien, los planes técnicos para el desarrollo de estas zonas agrícolas bonificadas insistían una y otra vez en la idoneidad de destinar estos recursos a los cultivos hortofrutícolas e industriales, que se entendían más adecuados para lo que debería 
haberse convertido en un potente sector agroindustrial, y aconsejaban dejar fuera de estos planes al olivar.

La adopción del regadío en el olivar no se generalizó, de hecho, hasta la década de los noventa del siglo pasado (Araque et al., 2002). Este hecho refuerza, no obstante, la idea que venimos defendiendo de que el olivar se va introduciendo en todas las lógicas productivistas a su alcance. En concreto, el aporte de agua ha permitido no solo aumentar sino, igualmente, regularizar las producciones de un cultivo prototípicamente vecero. De una significación apenas testimonial en 1956, el agua comporta ahora un elemento de primer orden para entender no solo el cultivo sino incluso el paisaje de la provincia de Jaén, salpicado de embalses y balsas de riego para este fin (figura 3 y figura 4). Más allá de servir para apreciar la importante ocupación de espacio por infraestructuras específicamente ligadas al cultivo del olivar (balsas), la cartografía obtenida refleja, no obstante, de forma bastante parca el avance del olivar regado. Así, frente a apenas 50 mil ha reflejadas en el mapa, la estadística oficial de ese año reconocía la existencia de una cifra superior a las $182.000 \mathrm{ha}$.

Figura 3. El olivar regado y la infraestructura de embalses y balsas.

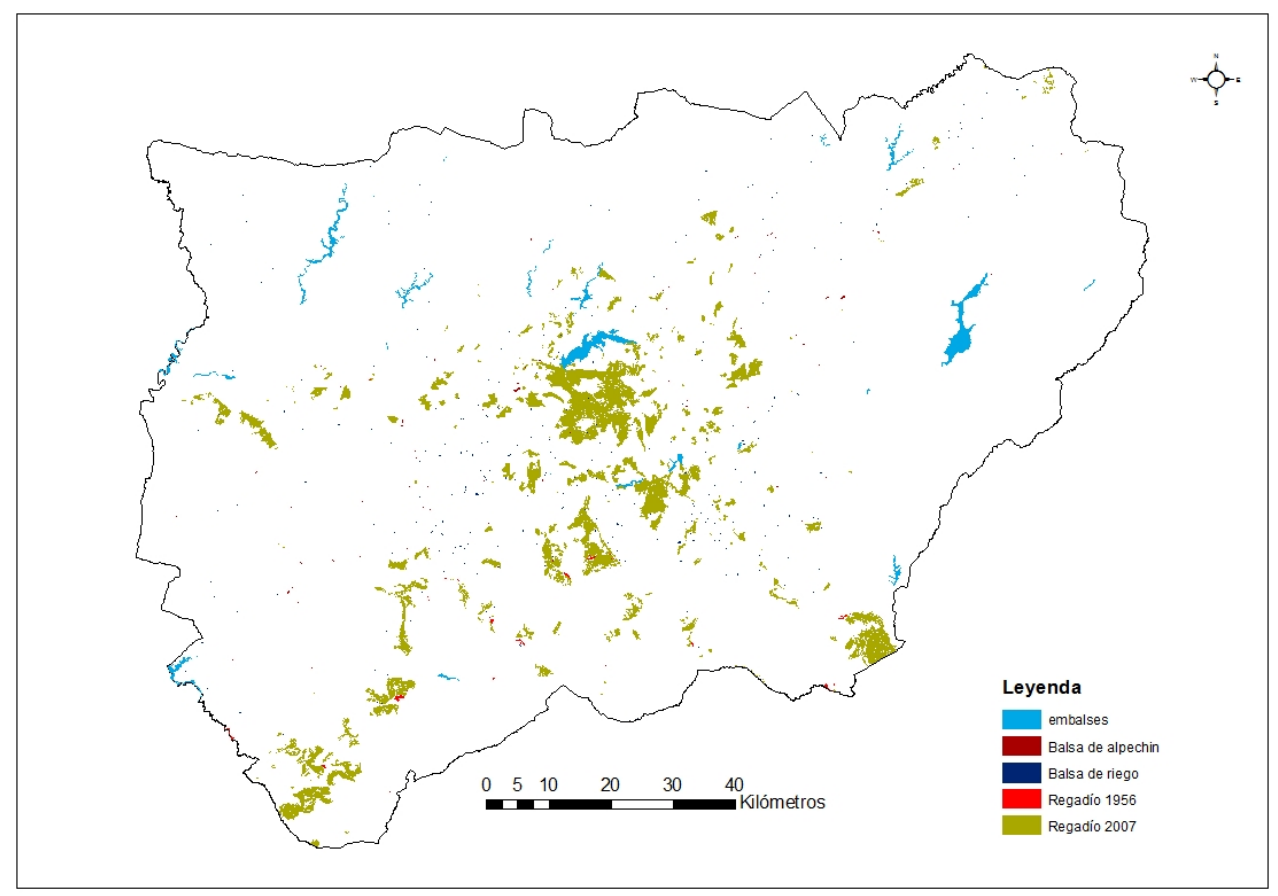

Fuente: Elaboración propia. 
Figura 4. Fotografía aérea de un ámbito con fuerte presencia de balsas para el riego del olivar (términos municipales de Jaén y Mancha Real).

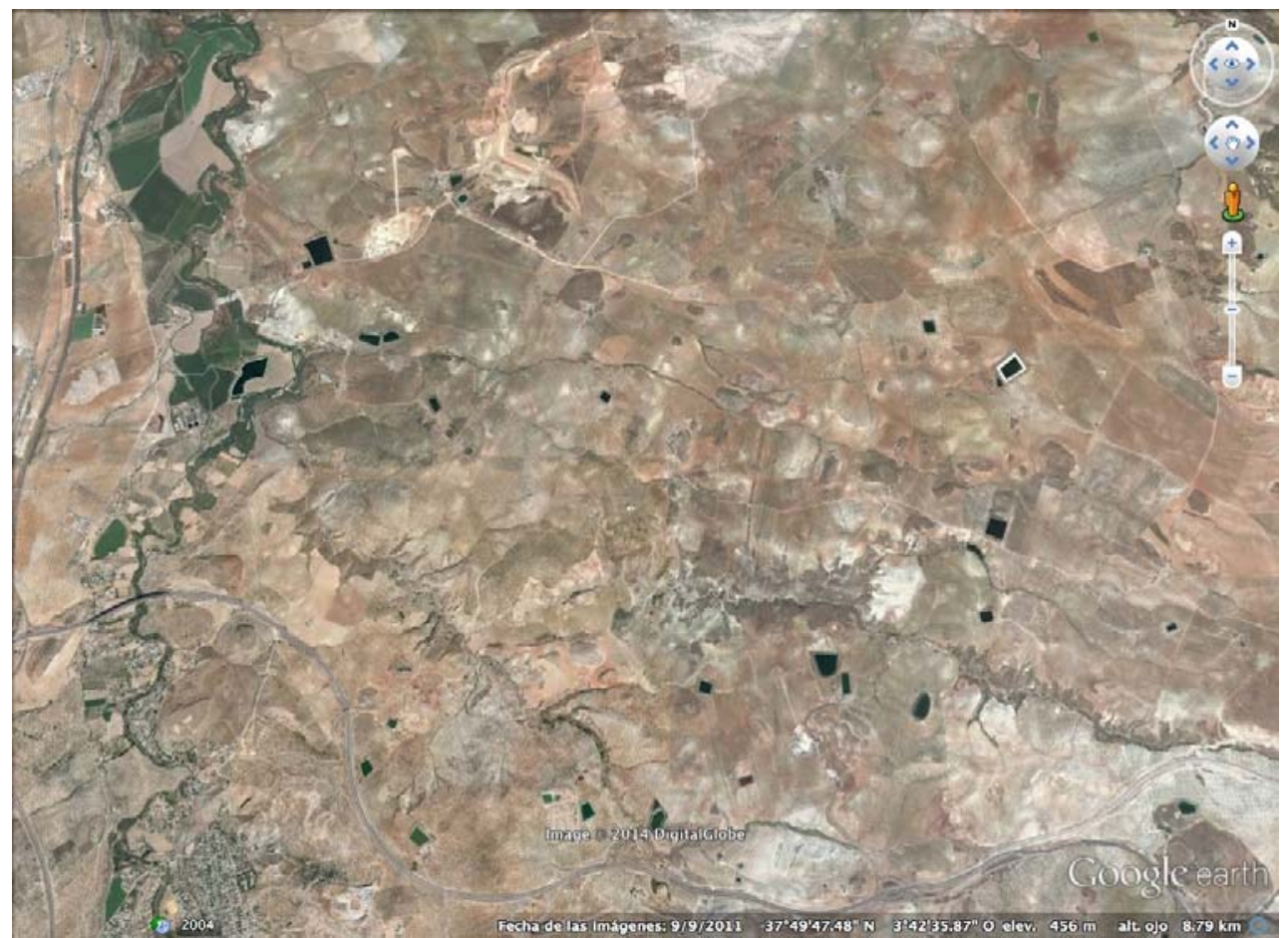

Fuente: Google Earth (acceso de 24 de noviembre de 2014).

Otra forma de constatar el salto del cultivo delo olivar hacia las tierras más fáciles de trabajar y fértiles es considerando su distribución espacial de acuerdo con la capacidad del suelo en los diferentes momentos que hemos cartografiado. En ese sentido, la metodología que hemos seguido es la superposición de las manchas de olivar de 1956 y 2007 sobre la distribución de grandes clases establecidas en el mapa de capacidad de uso y erosión del suelo del Atlas de Andalucía ${ }^{7}$. En este mapa el proceso de evaluación de capacidad combina diferentes variables fisiográficas (relieve, suelo, clima, agua, uso actual, vegetación y erosión), estableciéndose la pertenencia de un terreno a una clase de capacidad en relación con el factor natural que sea más limitante para el uso de esa tierra (fundamentalmente pendiente,

${ }^{7}$ http://www.juntadeandalucia.es/medioambiente (acceso de 10 de noviembre de 2014). 
profundidad útil, textura, drenaje y salinidad del suelo, grado de humedad y riesgo de helada). En total, se definen cuatro grandes clases:

- Tierras de excelente capacidad de uso, que carecen de limitaciones que restrinjan su uso, tienen una elevada productividad y no necesitan prácticas especiales de conservación para evitar la erosión.

- Tierras con buena capacidad de uso, que presentan algunas limitaciones y dificultades de manejo, si bien su productividad puede llegar a ser buena con manejo adecuado y prácticas moderadas de conservación del suelo.

- Tierras con moderada capacidad de uso, con limitaciones importantes que reducen su capacidad productiva y los usos posibles, necesitando técnicas de manejo y conservación complejas.

- Tierras con baja capacidad de uso y tierras marginales, que en general no reúnen condiciones adecuadas para el cultivo agrícola (tierras de vocación forestal).

El alcance superficial de cada una de estas clases agrológicas en la provincia y la evolución de su ocupación por el olivar (tabla 3 y figura 5) muestra claramente que, si bien la expansión es generalizada, se ha concentrado en las tierras de buena y moderada capacidad de uso. En las tierras excelentes la expansión, modesta en términos absolutos por la propia pequeñez de este tipo de tierras, es también muy significativa en términos relativos. En cambio, las ganancias menores se observan en las de baja y nula capacidad, si bien como decíamos antes no deja de ser significativo que incluso por estas tierras se haya seguido plantando olivar a pesar de las dificultades que su manejo implica. Desde luego una de las causas (la fundamental no obstante tiene que ver con el tipo de prácticas agrícolas que se han generalizado) de las elevadas pérdidas de suelo por erosión que presentan los olivares en la provincia de Jaén, es la significativa participación de este tipo de tierras en el cultivo, pues contrariamente a lo que realmente sucede, su correcta gestión requiere de costosas, complejas y continuas técnicas de conservación del suelo (Stroosnijde et al., 2008).

Tabla 3. Evolución de la superficie destinada al cultivo del olivar en relación con la capacidad de uso del suelo.

\begin{tabular}{|l|c|c|c|c|c|c|c|c|}
\hline & \multicolumn{2}{|c|}{ Provincia de Jaén } & \multicolumn{2}{c|}{ Olivar 1956} & \multicolumn{2}{c|}{ Olivar 2007 } & \multicolumn{2}{c|}{$\Delta 1956-2007$} \\
\hline Clase & Sup. (ha) & $\begin{array}{c}\text { Sup. } \\
(\%)\end{array}$ & Sup. (ha) & $\begin{array}{c}\text { Sup. } \\
(\%)\end{array}$ & Sup. (ha) & $\begin{array}{c}\text { Sup. } \\
(\%)\end{array}$ & $\begin{array}{c}\text { Sup. (ha) } \\
\text { Sup. } \\
(\%)\end{array}$ \\
\hline Excelente & $24.015,41$ & 1,78 & $5.055,70$ & 21,05 & $8.324,89$ & 1,46 & $3.269,19$ & 64,66 \\
\hline Buena & $279.749,86$ & 20,76 & $126.527,30$ & 45,23 & $218.242,00$ & 38,24 & $91.984,70$ & 72,85 \\
\hline Moderada & $375.488,14$ & 27,86 & $105.068,96$ & 27,98 & $183.274,00$ & 32,12 & $78.205,04$ & 74,43 \\
\hline Marginal & $668.306,20$ & 49,59 & $118.996,56$ & 17,81 & $160.814,00$ & 28,18 & $41.817,44$ & 35,14 \\
\hline Total & $1.347 .559,62$ & 100,00 & $335.378,52$ & 24,89 & $570.654,89$ & 100,00 & $215.276,37$ & 60,58 \\
\hline
\end{tabular}

Fuente: Elaboración propia. 
Figura 5. Distribución del olivar existente en 2007 según capacidad de uso del suelo.

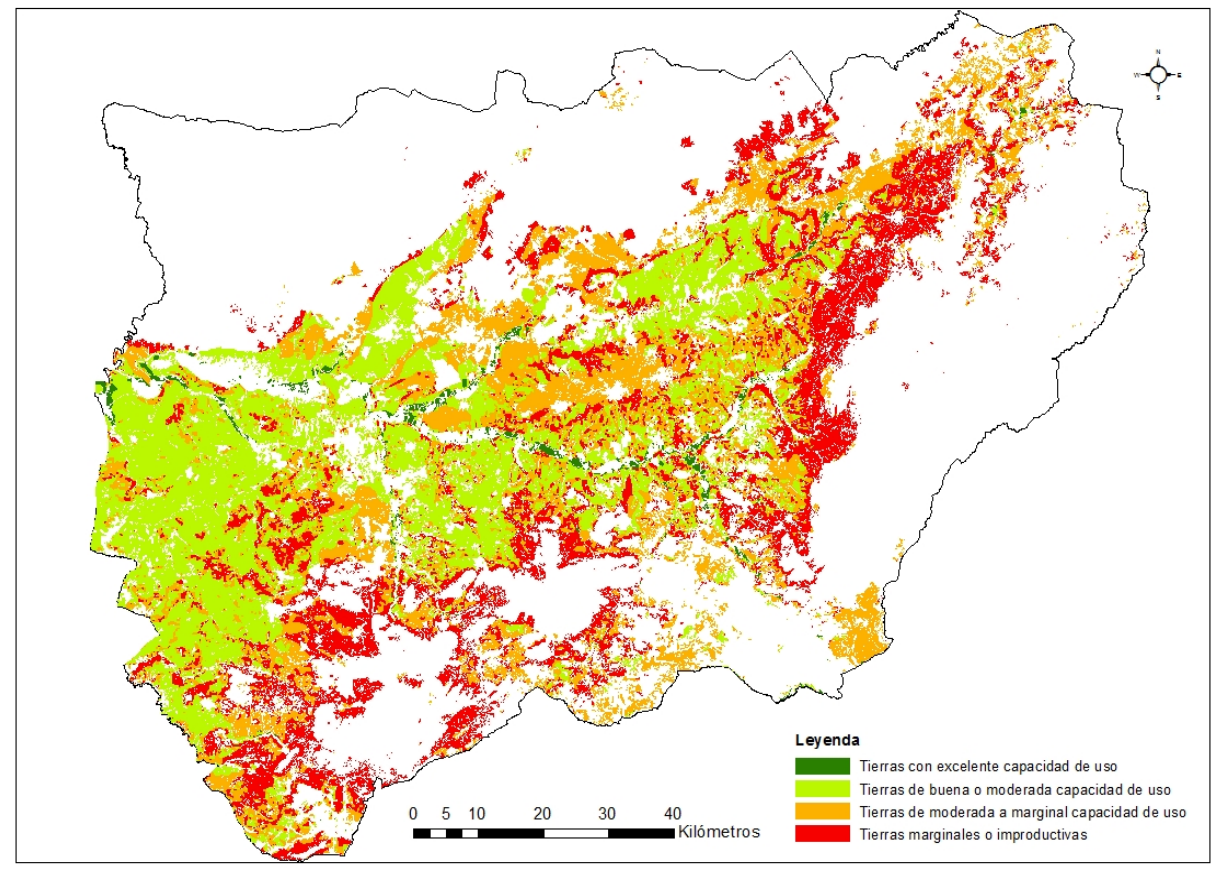

Fuente: Elaboración propia.

\section{CONCLUSIONES}

El empleo de fuentes cartográficas nos ha permitido localizar con precisión la fuerte expansión experimentada por el olivar en la provincia de Jaén desde mediados del siglo XX, que ha culminado en la formación de un monocultivo antológico. En ese sentido, la comparación con la información ofrecida por las fuentes estadísticas, si bien incurre en pequeñas discrepancias, no invalida el análisis respecto a una serie de características observables en este proceso.

La más destacada tiene que ver con su dimensión, resultando un crecimiento de más del 60\%. Las 215 mil ha que se sumaron entre 1956 y 2007 lo fueron, mayoritariamente, como resultado de un proceso de sustitución de usos en el suelo agrícola consolidado. Frente al mecanismo de la roturación, muy generalizado durante la segunda mitad del siglo XIX, los nuevos olivares jiennenses han venido a instalarse en tierras antes destinadas sobre todo al cereal, por lo general de buenas condiciones agronómicas. La razón fundamental de este cambio se encuentra en los estímulos recibidos por los agricultores desde el mercado y también respecto a las orientaciones de la política agraria española y europea. Bajo un marco muy favorable para la venta del aceite de oliva, el resultado ha sido un incremento espectacular de 
las cosechas, si bien se ha debido en mayor medida al incremento de los rendimientos que a la propia adicción de superficie cultivada. Una buena prueba de ello es la reconversión hacia el regadío de un cultivo que hasta entonces solo se concebía como propio de los secanos.

La colonización de las mejores tierras, incluso en los fondos de valle de las zonas irrigadas de calidad excelente convive, no obstante, con el mantenimiento de olivares que se sitúan en zonas de clara dificultad productiva. Es más, llama poderosamente la atención la existencia de roturaciones forestales para ampliar la frontera agrícola, una actividad que habría que considerar extraña y extemporánea si no fuera por la pujanza que el cultivo ha mantenido, especialmente desde la incorporación de España a la Unión Europea. Los olivares con más dificultades no solo no se han abandonado, sino que se han consolidado en una superficie muy considerable. Como consecuencia de ello, se ha llegado en la actualidad a una situación en la que conviven olivares de muy diferente condición y aptitud. Desde el punto de vista agronómico-paisajístico cabe señalar la existencia de diferentes categorías, que tienen que ver con la antigüedad y el marco de la plantación, el régimen de cultivo y la propia fisiografía de los terrenos ocupados (Asociación Española de Municipios del Olivo, 2010; Consejo Económico y Social de la Provincia de Jaén, 2011).

Algunas fotografías obtenidas en el trabajo de campo (Anexo I) permiten apreciar a grandes rasgos estas disparidades y, en general, la existencia de diferentes niveles de intensidad productiva dentro de dos grandes categorías: los olivares de sierra y los de campiña.

\section{BIBLIOGRAFÍA}

ASOCIACIÓN ESPAÑOLA DE MUNICIPIOS DEL OLIVO (2010). Aproximación a los costes del cultivo del olivo. Cuaderno de conclusiones del seminario AEMO. http://www.aemo.es/get.php?pathext=descargas/Costes_AEMO.pdf (acceso 10-06-2011)

ARAQUE, E. (2010). El olivar en la provincia de Jaén: evolución reciente y situación actual. En Araque, E.; Cuesta, M. J. y García, P. (coords.): Actas del Congreso de la Asociación Española de Ciencia Regional, Asociación Andaluza de Ciencia Regional, Jaén, 271-297.

ARAQUE, E., GALLEGO, V. J. y SÁNCHEZ, J. D. (2002). El olivar regado en la provincia de Jaén. Investigaciones Geográficas, 28, 5-32.

CONSEJO ECONÓMICO y SOCIAL DE LA PROVINCIA DE JAÉN (2011). Análisis de la rentabilidad económica de las explotaciones de olivar en la provincia de Jaén.

http://www.dipujaen.es/export/sites/default/galerias/galeriaDescargas/diputacion/dipu jaen/CES/otras_imagenes/DICTAMEN_DEL_CES_2010documento_final1.pdf (acceso 13-06-2011).

DIRECCIÓN GENERAL DEL INSTITUTO GEOGRÁFICO Y ESTADÍSTICO (1888). Reseña geográfico-estadística de España. Madrid. 
GUZMÁN, J. R.; GÓMEZ, J. A. y RALLO, L. (2009). El olivar en Andalucía: lecciones para el futuro de un cultivo milenario. En Gómez, J. A. (coord.): Sostenibilidad de la producción de olivar en Andalucía. Sevilla. Consejería de Agricultura y Pesca de la Junta de Andalucía, 7-19.

JUNTA DE ANDALUCÍA (1987). Evaluación ecológica de los recursos naturales de Andalucía. Sevilla. Agencia de Medio Ambiente.

JUNTA DE ANDALUCÍA (2005). Atlas de Andalucía (2). Cartografía Ambiental. Sevilla.

MINISTERIO DE AGRICULTURA (1975). Inventario agronómico del olivar. II Provincia de Jaén. Madrid. Dirección General de la Producción Agraria.

MINISTERIO DE AGRICULTURA, PESCA y ALIMENTACIÓN (1987). Mapa de cultivos y aprovechamientos de la provincia de Jaén. Escala 1:200.000. Madrid. Secretaría General Técnica.

MINISTERIO DE MEDIO AMBIENTE y MEDIO RURAL y MARINO (2010). Estudio de la cadena de valor y formación de precios del aceite de oliva.

http://www.magrama.gob.es (acceso de 25 de noviembre de 2014).

MOLINA, J. M. y REY, F. J. (1997). Geología de Vilches, En VV AA (1997): Jaén: Pueblos y Ciudades. Diario Jaén, 2702-2703.

PANIZA, A. (2010). Los paisajes del olivar: paisajes tradicionales y nuevos paisajes en el condado de Jaén. VI Sexto Congreso Internacional de Ordenación del Territorio Pamplona. FUNDICOT

http://media.wix.com/ugd/1c299f_2359236597d44138b1f5b7383a1dff5b.pdf

(acceso del 26 de noviembre de 2014)

RODRÍGUEZ, J. C.; SÁNCHEZ, J. D. y GALLEGO, V. J. (2013). Valorizando el territorio con alimentos excelentes: los aceites de alta gama en el sur de España. ARETHUSE. Rivista di studi economico-gestionali, 1, 75-89.

RUIZ, P., (1997). Geología de Jaén. En VV AA (1997): Jaén: Pueblos y Ciudades. Diario Jaén, 15-23.

SÁNCHEZ, J. D. (2012). Una contribución al debate sobre los monocultivos: la especialización olivarera de Andalucía (España). GEO - UERJ, 23, 19-52. (acceso de 24 de noviembre de 2014).

http://www.e-publicacoes.uerj.br/index.php/geouerj/article/view/3683/2563

SÁNCHEZ, J. D.; ARAQUE, E. y GALLEGO, V. J. (2011). El olivar en la España del sur: dinámicas y perspectivas de un monocultivo extremo. Lurralde: investigación y espacio, 34, 273-299.

SÁNCHEZ, J. D. y GALLEGO, V. J. (2011). La nueva reconversión productiva del olivar jiennense: aproximación inicial a sus fundamentos y limitaciones. Cuadernos Geográficos, 49, 95-121.

STROOSNIJDER, L. MANSIHO, M. I. y PALESE, A. M. (2008). OLIVERO: The Project analysisng the future of olive production systems on sloping land in the Mediterranean basin. Journal of Environmental Management, 89, 75-85.

UNITED STATES INTERNATIONAL TRADE COMMISSION (2013). Olive Oil: Conditions of Competition between U.S. and Major Foreign Supplier Industries. 


\section{ANEXO I}

Figura 1. Olivar sobre tierras marginales. Cerro de la Vicaría (Jaén).

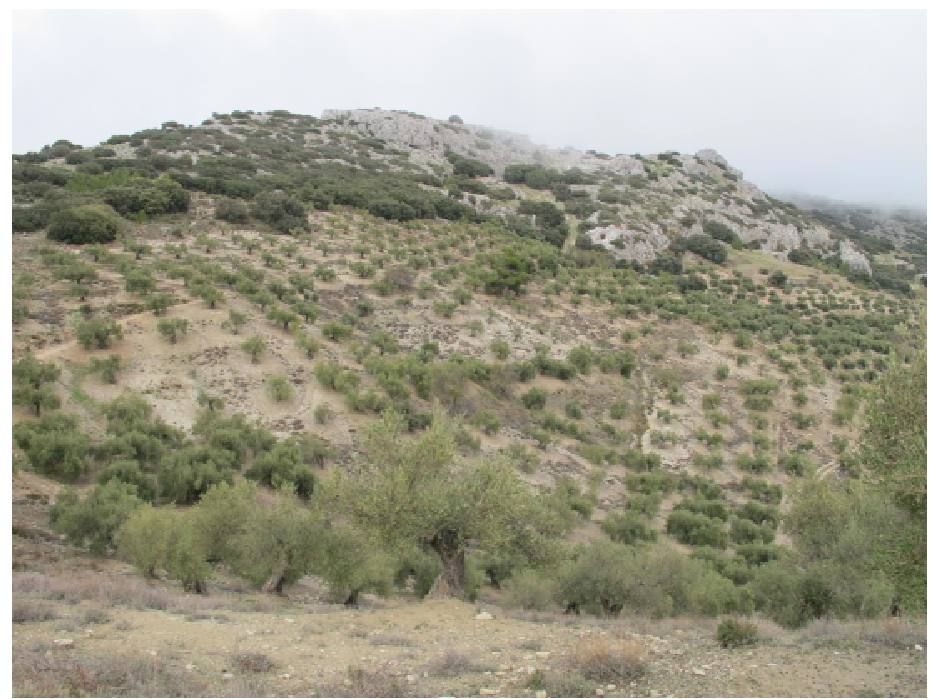

Fuente: José D. Sánchez Martínez (2014).

Figura 2. Olivar en tierras de moderada capacidad de uso en el arranque de Sierra Mágina (Mancha Real).

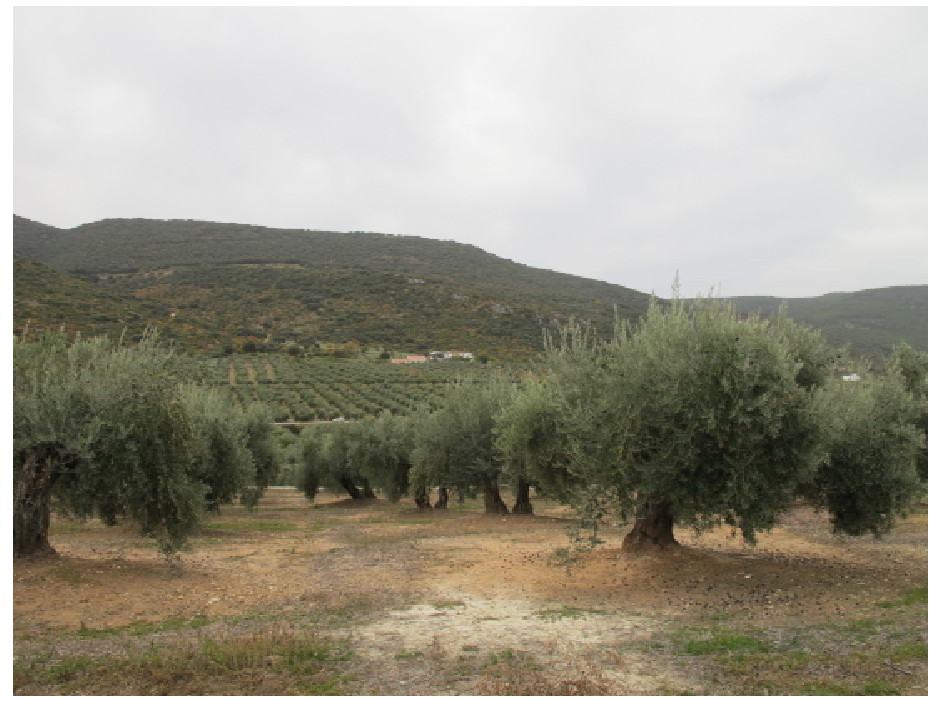

Fuente: José D. Sánchez Martínez (2014). 
Figura 3. Olivar joven de alta densidad en tierras de buena capacidad. Loma de Úbeda (Villacarrillo).

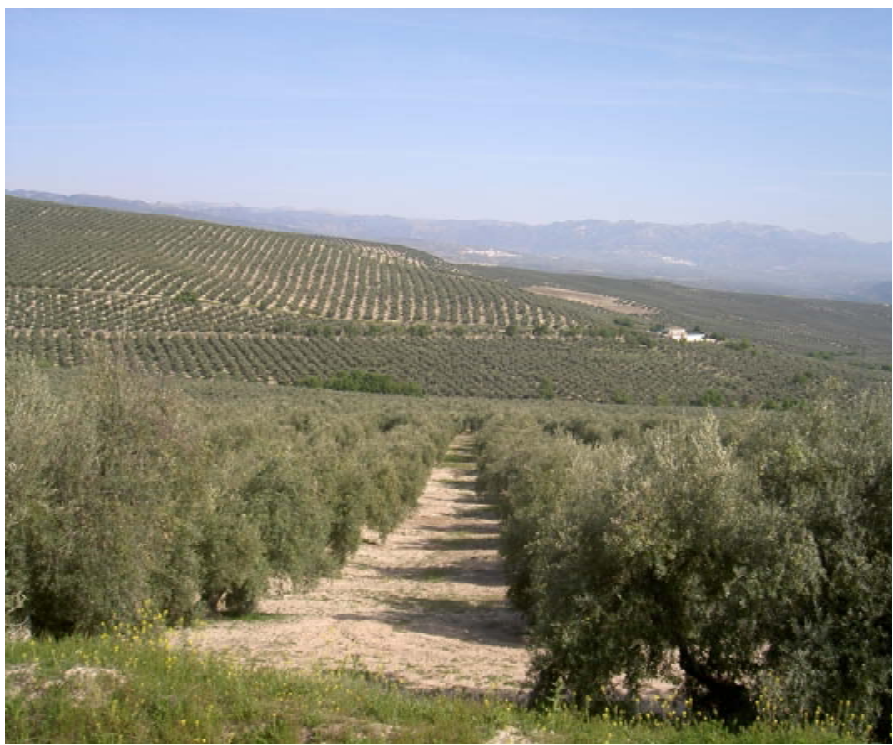

Fuente: José D. Sánchez Martínez (2014).

Figura 4. Olivar de alta densidad en tierras de excelente capacidad. Terrazas del Guadalquivir (Baeza).

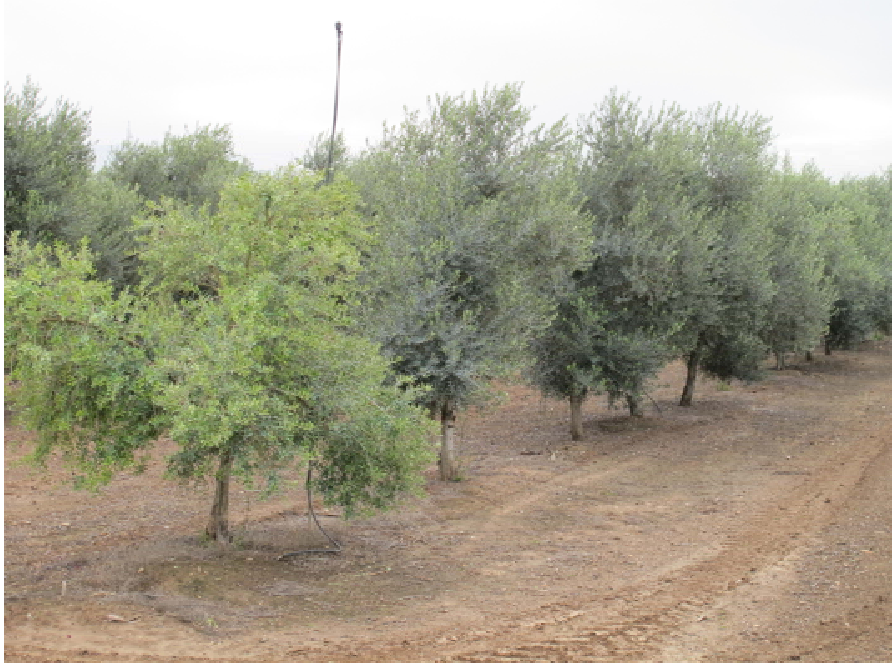

Fuente: José D. Sánchez Martínez (2014). 